\title{
Room-temperature polymerization of $\beta$-pinene by niobium and tantalum halides
}

Mohammad Hayatifar, Fabio Marchetti, Guido Pampaloni, Yogesh Patil, Anna Maria Raspolli Galletti* Department of Chemistry and Industrial Chemistry, University of Pisa, via Risorgimento 35, 56126 Pisa, Italy.

\begin{abstract}
The easily accessible niobium pentahalides $\mathrm{NbX}_{5}(\mathrm{X}=\mathrm{F}, \mathbf{1} \mathbf{a} ; \mathrm{X}=\mathrm{Cl}, \mathbf{1 b} ; \mathrm{X}=\mathrm{Br}, \mathbf{1} \mathbf{c})$ and the tantalum $\mathrm{TaF}_{5}$ (2a) were employed for the first time as effective catalysts for the synthesis of poly- $\beta$-pinene at room temperature. ${ }^{1} \mathrm{H}$ NMR analyses indicated that the produced $\beta$-pinene polymers were structurally identical to that formed by conventional cationic Lewis acid initiators. Niobium pentachloride gave low molecular weight $\left(M_{n}=1200-1600\right)$ polymer with high conversion degree. The effects of the main reaction parameters (i.e. solvent, temperature, catalyst concentration, time and eventual co-catalysts) on the $\mathrm{NbCl}_{5}$-promoted polymerization were investigated. Polymerization quenching with methanol resulted in incorporation of a methoxy-end group into the polymer chain, thus suggesting a cationic mechanism. NMR investigations and analytical measurements outlined that the reactions of $\mathbf{1 a}, \mathbf{b}$ with limited amounts of $\beta$-pinene afforded $\mathrm{Nb}(\mathrm{V})$ ionic derivatives. On the other hand, $\mathrm{NbI}_{5}, \mathrm{TaCl}_{5}$, the carbamato-complexes $\mathrm{M}\left(\mathrm{O}_{2} \mathrm{CNEt}_{2}\right)_{5}(\mathrm{M}=\mathrm{Nb}, \mathrm{Ta})$ and the mononuclear adducts $\mathrm{NbX}_{5} \mathrm{~L}[\mathrm{X}=\mathrm{Cl}, \mathrm{L}=$ $\mathrm{MeCN}, \mathrm{Ph}_{2} \mathrm{CO}$ or $\left.\left(\mathrm{NMe}_{2}\right)_{2} \mathrm{CO} ; \mathrm{X}=\mathrm{F}, \mathrm{L}=\mathrm{EtOH}\right]$ were not active in $\beta$-pinene polymerization.
\end{abstract}

Keywords: $\beta$-pinene; cationic polymerization; Lewis acids; niobium halides; tantalum halides.

*corresponding author (e-mail: roxy@dcci.unipi.it; phone: 003950 2219290; fax: 003950 2219260). 


\section{Introduction}

$\beta$-Pinene is the most important distillation product of natural turpentine [1]. Its commercially available polymer (terpene resin) is used in a wide variety of industrial applications (e.g. adhesives and varnishes, bituminous materials, tackifying agents, additives in rubber [2,3]), because it exhibits a combination of desired and outstanding properties. For instance, high solubility in hydrocarbon solvents, compatibility with waxes and relatively high softening point $\left(125-135^{\circ} \mathrm{C}\right)$. Moreover the polymer is nontoxic and inert to common chemicals, that makes it suitable for the food packaging and the production of chewing gums [4]. Furthermore, due to the limited fossil resources, terpene resins, derived from renewable resources, have aroused increasing interest in both academic and industrial context as outstanding biomaterials.

A variety of polymerization techniques have been employed for the polymerization of $\beta$-pinene in recent years, i.e. the Ziegler-Natta type, the free-radical, the cationic and the radiation-induced cationic polymerization [4,5]. Lewis acid-promoted cationic polymerization represents the most efficient method in the commercial production of poly( $\beta$-pinene). The presence of two alkyl groups on the double bond determines rapid cationic polymerization of $\beta$-pinene with conventional or even living fashion [6]. The resulting polymers have alternating sequences of isobutylene and cyclohexene units (Fig. 1).

Fig. 1. near here 
Different Lewis acids $\left(\mathrm{AlCl}_{3}, \mathrm{SnCl}_{4}, \mathrm{ZnCl}_{2}, \mathrm{ZrCl}_{4}, \mathrm{BF}_{3}\right.$ etc. $)$ have been used for the polymerization of $\beta$ pinene $[7,8,9,10,11,12,13$,$] and the results reported in the literature have been summarized in Table$ 1.

Table 1 near here

The catalytic conversion of $\beta$-pinene to polymer was studied with a number of Friedel-Crafts catalysts (Runs 4-13, Table 1) at fixed conditions. The results demonstrate that $\beta$-pinene polymerizes very fast and in a vigorous way after less than $1 \%$ of aluminum chloride is added; otherwise the conversion degree was much lower when $\mathrm{SbCl}_{3}$ and $\mathrm{ZnCl}_{2}$ were employed as catalysts. As far as aluminium alkyls are concerned, it has been observed that lower temperatures favour the global yield of the polymerization process using ethylaluminium dichloride [10], while an increase in the temperature of polymerization gave rise to resins of lower molecular weight, lower softening point, and darker color.

More recently, Zhou et al. [14] have stated that Keggin-type heteropolyacids (HPAs) are environmental friendly, have high Brønsted acidity and are efficient catalyst in the cationic polymerization of $\beta$-pinene.

Niobium and tantalum pentahalides are strong Lewis acids, easily available and biocompatible metalbased compounds [15] which are attaining increasing popularity as chemical reagents. In this contribution, we report a study on the polymerization reaction of $\beta$-pinene mediated by $\mathrm{MX}_{5}(\mathrm{M}=\mathrm{Nb}$ or Ta; $\mathrm{X}=$ halide) [16] or their derivatives. We have found that $\mathrm{NbCl}_{5}$ is an efficient catalyst leading to smooth and quantitative polymerization at room temperature. The effects of the reaction conditions, including the possible use of alkylaluminum co-catalysts, on the $\mathrm{NbCl}_{5}$-mediated polymerization will be discussed. 


\section{Experimental}

\subsection{General}

All manipulations of air and/or moisture sensitive compounds were performed under atmosphere of prepurified Argon using standard Schlenk techniques. The reaction vessels were oven dried at $150{ }^{\circ} \mathrm{C}$ prior to use, evacuated $\left(10^{-2} \mathrm{mmHg}\right)$ and then filled with $\operatorname{argon} . \mathrm{NbX}_{5}(\mathrm{X}=\mathrm{F}, \mathbf{1 a} ; \mathrm{X}=\mathrm{Cl}, \mathbf{1 b} ; \mathrm{X}=\mathrm{I}, \mathbf{1 d})$ and $\mathrm{TaX}_{5}(\mathrm{X}=\mathrm{F}, \mathbf{2 a} ; \mathrm{X}=\mathrm{Cl}, \mathbf{2 b})$ were commercial products (Strem) of the highest purity available, stored under argon atmosphere as received. $\mathrm{NbBr}_{5}(1 \mathrm{c})$ [17] $\mathrm{NbF}_{4}(\mathrm{OPh})[18], \mathrm{M}\left(\mathrm{O}_{2} \mathrm{CNEt}_{2}\right)_{5}(\mathrm{M}=\mathrm{Nb}, \mathrm{Ta})[19]$, and $\mathrm{NbX}_{5} \mathrm{~L}\left(\mathrm{X}=\mathrm{Cl}, \mathrm{L}=\mathrm{MeCN}\right.$ [20], $\mathrm{Ph}_{2} \mathrm{CO}$ [21] or $\left(\mathrm{NMe}_{2}\right)_{2} \mathrm{CO}$ [22]; X = F, L = EtOH [23] $)$ were prepared according to published procedures. Solvents were purchased from Sigma-Aldrich and distilled before use from appropriate drying agents. All the organic reactants and ethylaluminumdichloride (EADC; 25 wt.\% in toluene), diethylaluminumchloride (DEAC; 25\% w/w in toluene), methylaluminoxane (MAO; $10 \% \mathrm{w} / \mathrm{w}$ in toluene), trimethylaluminum (TMA; $2 \mathrm{M}$ in toluene), triisobutylaluminum (TIBAL; 25\% w/w in toluene) were used as received (Sigma-Aldrich) without further purification.

Infrared spectra were recorded at $298 \mathrm{~K}$ on a FT IR-Perkin Elmer Spectrometer, equipped with a UATR sampling accessory. NMR spectra were recorded on Bruker Avance DRX400 instrument equipped with probe BBFO broadband. Unless otherwise stated, NMR spectra were recorded at $298 \mathrm{~K}$. The ${ }^{1} \mathrm{H}-$ and the

${ }^{13} \mathrm{C}$ spectra were assigned via DEPT experiments and ${ }^{1} \mathrm{H},{ }^{13} \mathrm{C}$ correlation measured through gs-HSQC and gs-HMBC experiments [24]. The chemical shifts for ${ }^{1} \mathrm{H}$ and ${ }^{13} \mathrm{C}$ were referenced to the nondeuterated aliquot of the solvent; the chemical shifts for ${ }^{19} \mathrm{~F}$ were referenced to $\mathrm{CFCl}_{3}$; the chemical shifts for ${ }^{93} \mathrm{Nb}$ were referenced to $\left[\mathrm{NEt}_{4}\right]\left[\mathrm{NbCl}_{6}\right]$. Molar conductivities $\left(\Lambda_{\mathrm{M}}\right)$ measurements were carried 
out with Eutech Con 700 Instrument (cell constant $=1.0 \mathrm{~cm}^{-1}$ ) at $298 \mathrm{~K}$ [25]. Carbon and hydrogen analyses were performed on Carlo Erba mod. 1106 instrument. The chloride content was determined by the Volhardt method [26] after exhaustive hydrolysis of the sample. The metal was analyzed as $\mathrm{Nb}_{2} \mathrm{O}_{5}$, obtained by hydrolysis of the sample followed by calcination in a platinum crucible. $\mathrm{The} \mathrm{Cl}$ and $\mathrm{Nb}$ analyses were repeated twice in order to check for reproducibility.

The molecular weights and the molecular weight distributions of the polymer samples were measured with a gel permeation chromatograph (GPC) instrument, PL 220, at room temperature in $\mathrm{CHCl}_{3}$ on $\mu$ Styragel columns $(106,105,104,103,500 \AA)$ connected with a refractive-index detector with polystyrene as standard.

\subsection{Polymerization of $\beta$-pinene}

$\beta$ - pinene polymerization experiments were carried out in a $50 \mathrm{~mL}$ Carius vessel under magnetic stirring and dry argon atmosphere. Carius vessel was covered with aluminum foil in order to avoid light. In a general procedure, the metal compound and the solvent (ca. $20 \mathrm{~mL}$ ) were transferred into the Carius vessel in the order given. Then $\beta$-pinene $(5 \mathrm{~mL})$ was added. Immediate change of color of the solution from colorless to yellow was always observed. During all the polymerization experiments, the temperature of the reaction was controlled by a thermostated bath. The polymerization was quenched by pouring the reaction mixture into a large excess of methanol acidified with $5 \%$ aqueous $\mathrm{HCl}$. Thus the white polymer was isolated by filtration, washed with methanol, dried in vacuum, weighed and characterized. 
2.3. Synthesis, isolation and characterization of coordination compounds of $N b X_{5}(X=F, C l)$ with $\beta$ pinene.

$\beta$-pinene $(2.20 \mathrm{mmol})$ was added to $\mathrm{NbF}_{5}(2.20 \mathrm{mmol})$ in pentane $(20 \mathrm{~mL})$. The mixture was stirred for 12 hours, then an ochre-yellow solid was isolated from a colourless solution. The solid was washed with pentane $(2 \times 10 \mathrm{~mL})$ and dried under vacuo. Anal. Calcd. for $\mathrm{C}_{10} \mathrm{H}_{16} \mathrm{~F}_{5} \mathrm{Nb}: \mathrm{C}, 37.05 ; \mathrm{H}, 4.98 ; \mathrm{Nb}, 28.66$. Found: C, 35.88; H, 5.07; Nb, 28.97. IR (solid state): 2961w, 2931w, 2870w, 1526m, 1464m, 1368w-m, $1261 \mathrm{~m}-\mathrm{s}, 1091 \mathrm{~s}, 1022 \mathrm{~s}, 896 \mathrm{~m}, 859 \mathrm{~m}, 797 \mathrm{vs} \mathrm{cm}^{-1}$.

The reaction of $\beta$-pinene $(2.35 \mathrm{mmol})$ with $\mathrm{NbCl}_{5}(2.35 \mathrm{mmol})$ was performed analogously and afforded an ochre-yellow solid. Anal. Calcd. for $\mathrm{C}_{10} \mathrm{H}_{16} \mathrm{Cl}_{5} \mathrm{Nb}$ : C, 29.55; H, 3.97; Nb, 22.86; Cl, 43.62. Found: C, 28.74; H, 3.75; Nb, 23.20; Cl, 42.64. IR (solid state): 2954w, 2925w, 2868w, 1587w-m, 1519m, $1462 \mathrm{~m}-\mathrm{s}, 1384 \mathrm{w}, 1366 \mathrm{w}-\mathrm{m}, 1262 \mathrm{w}, 1101 \mathrm{~m}, 872 \mathrm{~s}, 814 \mathrm{~s}, 779 \mathrm{vs} \mathrm{cm}{ }^{-1}$.

Conductivity analysis: a mixture of $\mathrm{NbX}_{5}(1.05 \mathrm{mmol})$ and $\mathrm{CH}_{2} \mathrm{Cl}_{2}(20 \mathrm{~mL})$ was treated with $\beta$-pinene (1.05 mmol). Rapid dissolution of the solid into a dark-red solution was observed. $\Lambda_{\mathrm{M}}=1.7 \mathrm{~S} \cdot \mathrm{cm}^{2} \cdot \mathrm{mol}^{-1}$ $(\mathrm{X}=\mathrm{F}) ; \Lambda_{\mathrm{M}}=2.1 \mathrm{~S} \cdot \mathrm{cm}^{2} \cdot \mathrm{mol}^{-1}(\mathrm{X}=\mathrm{Cl})$. Then additional two molar equivalents of $\beta$-pinene were added and the mixture was stirred for 15 minutes. $\Lambda_{\mathrm{M}}=2.0 \mathrm{~S} \cdot \mathrm{cm}^{2} \cdot \mathrm{mol}^{-1}(\mathrm{X}=\mathrm{F}) ; \Lambda_{\mathrm{M}}=3.0 \mathrm{~S} \cdot \mathrm{cm}^{2} \cdot \mathrm{mol}^{-1}(\mathrm{X}=$ Cl).

\section{Results and Discussion}

The results of $\beta$-pinene polymerization catalyzed by $\mathrm{NbCl}_{5}$ are represented in Table 2. Preliminary experiments were carried out in the presence or in the absence of visible light (Runs 17 and 18, respectively), in order to exclude the possibility of light-induced radical polymerization. The fact that 
similar conversion degrees and molecular weights were achieved in both conditions suggests that probably the polymerization reaction does not occur via radical pathway.

Table 2 near here

It was not possible to polymerize $\beta$ - pinene in the absence of $\mathrm{NbCl}_{5}$ (Run 19). Conversely, almost quantitative conversion of monomer to polymer was ascertained in the presence of $\mathrm{NbCl}_{5}$ (Run 17).

We performed the $\beta$-pinene polymerization reaction by using $\mathrm{NbCl}_{5}$ as catalyst under different experimental conditions, with the aim to see the influence of temperature, catalyst concentration, solvent, time, and co-catalyst.

In spite of the fact that the most favourable temperature range for the $\mathrm{AlCl}_{3}$-directed $\beta$-pinene polymerization was reported to be $-50 \div-10{ }^{\circ} \mathrm{C}$ (Table 1 ), the polymerization reaction with $\mathrm{NbCl}_{5}$ was very slow at $0{ }^{\circ} \mathrm{C}$ (Run 20). Moreover a decrease of $\beta$-pinene conversion, as well as of polymer molecular weight, was ascertained at $50{ }^{\circ} \mathrm{C}$ (Run 21). These data suggest that the optimal performance of the catalyst can be achieved approximately at room temperature.

When toluene was replaced by chlorobenzene as reaction medium, a significant decrease of polymerization [from $98 \%$ to $4 \%$ in 5 hours (Run 22)] was observed, thus suggesting that solvents with higher dielectric constant have a negative effect on the rate of polymerization. The effect of the nature of the solvent in cationic polymerization is often difficult to predict: the solvent with higher dielectric constant gives more "free" carbocations, but may also increase the activation energy of propagation step, thus resulting in lower polymerization rates [27].

It was also observed that the molecular weight of poly( $\beta$-pinene) obtained by adopting a lower reaction time came almost unchanged (compare Runs 17 and 23). This indicates the short lifetime of the 
propagating species. Remarkably, the increase of $\mathrm{NbCl}_{5}$ concentration from 15 to $30 \mu \mathrm{mol}$ sustained the monomer conversion degree and polymer molecular weight (compare Runs 17 and 24, Table 2).

In view of the fact that organoaluminum-based co-catalysts, e.g. MAO, TMA and TIBAL, generally play important roles in olefin polymerization [28], in terms of generation of active catalytic species, polymerization activity and molecular weight of polymers, we decided to test the polymerization reaction of $\beta$-pinene in the presence of aluminum co-catalysts. Besides, in the polymerization of $\beta$ pinene with nickel derivatives, it was ascertained that MAO helps to initiate the cationic polymerization forming an alkylated metal cation [29]. The obtained results (compare Run 17 with Run 25) inidicate that MAO did not influence conversion and polymer characteristics. On the other hand, the introduction of TMA and TIBAL provided negative effect both on the monomer conversion (compare Run 17 with Runs 26-27), while no effect was observed on the average molecular weight of the polymer. This means that the interaction of $\mathrm{NbCl}_{5}$ with the co-catalysts presumably generates metal species which are less effective than $\mathrm{NbCl}_{5}$ as $\beta$-pinene polymerization promoters. More in detail, the addition of TMA and TIBAL, which are strong reducing agents, could result in reduction of the niobium chloride to lower valent compounds [30]. It is worth mentioning that no catalytic activity was ascertained in the blank runs carried out by using Al-based compounds in the absence of $\mathrm{NbCl}_{5}$ (Runs 28-30). The exceptions are represented by acid co-catalysts ethylaluminumdichloride (EADC) and diethylaluminumchloride (DEAC), which produced appreciable amounts of poly( $\beta$-pinene) with high monomer conversions (86 and $95 \%$ respectively, Runs 31,32). Notwithstanding the conversion values are lower than that obtained by using $\mathrm{NbCl}_{5}$ only (98\%). As expected, the use of combined $\mathrm{NbCl}_{5} / \mathrm{EADC}$ or $\mathrm{NbCL}_{5} / \mathrm{DEAC}$ (Runs 33, 34) resulted in enhancement of the conversion degree, while the polymer average molecular weight did not significantly change. 
As far as niobium pentafluoride and pentabromide are concerned, we observed lower performances with respect to $\mathrm{NbCl}_{5}$ (see Table 3, Runs 35,36), while $\mathrm{NbI}_{5}$ was totally inactive. The result is not surprising for what concerns $\mathrm{NbBr}_{5}$ and $\mathrm{NbI}_{5}$, on account of the higher steric demand exerted by the heavier halide ligands with respect to the chloride. This steric effect may provide inertness to the niobium species resulting in progressively lower polymerization rates. Actually, we have recently reported that $\mathrm{NbBr}_{5}$ derivatives are less active than analogous $\mathrm{NbCl}_{5}$ derivatives in ethylene polymerization [31].

The low activity observed when using the strongly acidic $\mathrm{NbF}_{5}$ could be a consequence of the tetranuclear structure of the former in comparison with the dinuclear structures of $\mathrm{NbX}_{5}(\mathrm{X}=\mathrm{Cl}, \mathrm{Br}, \mathrm{I})$ [16]. The possibility of a strong dependence of the polymerization activity from the nuclearity of the metal precursor prompted us to study the $\beta$-pinene polymerization reaction with mononuclear coordination compounds such as $\mathrm{NbF}_{5}(\mathrm{EtOH})$ and $\mathrm{NbCl}_{5} \mathrm{~L}\left(\mathrm{~L}=\mathrm{MeCN}, \mathrm{Ph}_{2} \mathrm{CO},\left(\mathrm{NMe}_{2}\right)_{2} \mathrm{CO}\right)$. However, these derivatives did not reveal good candidates as polymerization catalysts (see Table 3 ). In the same way, the substitution of one fluoride ligand with a phenoxy group, in the tetranuclear structure of $\mathrm{NbF}_{5}$, did result in lower catalytic performance and lower molecular weight (compare Run 38 with Run 35) .

According to the general trend that niobium-based catalysts supply activities higher than those of their tantalum counterparts in ethylene polymerization [32], $\mathrm{TaCl}_{5}$ did produce trace amounts of poly- $\beta$ pinene and $\mathrm{TaF}_{5}$ was less efficient than $\mathrm{NbF}_{5}$ (compare Run 17 with 44 and Run 35 with 43, respectively).

Table 3, near here

Finally, the carbamato complex $\mathrm{Nb}\left(\mathrm{O}_{2} \mathrm{CNEt}_{2}\right)_{5}$, that is much more efficient than the parent compound $\mathrm{NbCl}_{5}$ in ethylene polymerization $[33,34]$, was taken in consideration. No polymer was formed both in the presence and in the absence of co-catalyst (Runs 45 and 46, Table 3). This is in agreement with the 
presumed cationic character of the $\beta$-pinene polymerization, which may be favoured by strong Lewis acids. Similar results were obtained when using $\mathrm{Ta}\left(\mathrm{O}_{2} \mathrm{CNEt}_{2}\right)_{5}$ as catalyst (Runs 47 and 48, Table 3 ).

${ }^{1} \mathrm{H}$ NMR and IR analyses have outlined that the poly- $\beta$-pinene obtained with $\mathrm{NbCl}_{5}$ as catalytic precursor is structurally identical to that formed by conventional cationic initiating systems [29].

The polymerization reaction was quenched by using a methanol/ $\mathrm{HCl}$ solution. As a matter of fact, the ${ }^{1} \mathrm{H}$ NMR analysis of the polymeric material (Figure 2) pointed out that a methoxy group (resonance at $3.5 \mathrm{ppm}$ ) was present as the terminal group of the polymer chain. This is consequence of the formal addition of the $\left[\mathrm{MeO}^{-}\right]$ion to the terminal carbocation of the growing chain [29]. Analogously, the IR spectra of the poly- $\beta$-pinene samples showed two absorptions at 1160 to $836 \mathrm{~cm}^{-1}$ which have been assigned to $\mathrm{C}-\mathrm{O}-\mathrm{C}$ stretching vibrations related to the $\mathrm{C}-\mathrm{O}-\mathrm{CH}_{3}$ group. The characteristics endoolefinic band at $1666 \mathrm{~cm}^{-1}$ was also present.

Fig. 2 and Fig. 3. near here

In order to collect information about the possible mechanism involved in the polymerization of $\beta$-pinene mediated by $\mathrm{Nb}(\mathrm{V})$ pentahalides, we studied the $1: 1$ molar reactions of $\mathrm{NbX}_{5}(\mathrm{X}=\mathrm{F}, \mathrm{Cl})$ with the monomer. In both cases, a solid product of empirical formula " $\mathrm{NbX} 5(\beta$-pinene)" could be isolated by performing the reactions in pentane (see Experimental). According to conductivity measurements, the coordination compounds formed in the reactions of $\mathrm{NbX}_{5}(\mathrm{X}=\mathrm{F}, \mathrm{Cl})$ with $\beta$-pinene are ionic, probably formed as result of some halide transfer. In fact, the values of molar conductivity fall in the range typical for ionic derivatives of $\mathrm{MX}_{5}\left(\mathrm{M}=\mathrm{Nb}\right.$, Ta) [35]. The alkene molecules in " $\mathrm{NbX}_{5}(\beta$-pinene)" are 
probably coordinated by the $[\mathrm{C}=\mathrm{C}]$ double bond to the metal centre, as suggested by IR and NMR spectroscopy. More in detail, the IR spectra displayed a medium-intensity band at ca. $1520 \mathrm{~cm}^{-1}$, ascribable to a coordinated carbon-carbon double bond [36]. Moreover the ${ }^{1} \mathrm{H}$ NMR spectra recorded on the reaction mixtures $\mathrm{NbX}_{5} / \beta$-pinene (molar ratio $=1$ ) displayed broad resonances at low fields ascribable to protons bound to coordinated $\mathrm{Cs} p^{2}$-carbons [37]. Presumably " $\mathrm{NbCl}_{5}(\beta$-pinene)" holds a lower nuclearity than " $\mathrm{NbF}_{5}\left(\beta\right.$-pinene)", see above. The ${ }^{19} \mathrm{~F}$ NMR spectrum for $\mathrm{NbF}_{5} / \beta$-pinene showed a broad resonance at ca. $160 \mathrm{ppm}$; low temperature NMR experiment was not helpful in freezing the presumably operative exchange process [23].

The isolation of possible ionic intermediate may explain the high efficiency of $\mathrm{NbCl}_{5}$ as promoter of the polymerization of $\beta$-pinene, in view of the increased Lewis acidity on going from the neutral $\mathrm{NbCl}_{5}$ to cationic derivatives.

\section{Conclusion}

The polymerization of $\beta$-pinene has been conveniently carried out at room temperature by employing $\mathrm{NbCl}_{5}$ as catalyst, and the main reaction parameters (temperature, time, catalyst concentration, solvent) have been optimized. Other $\mathrm{Nb}(\mathrm{V})$ halides and $\mathrm{TaF}_{5}$ are also effective as catalysts, although providing performances lower than that of $\mathrm{NbCl}_{5}$. The presence of oxygen ligands in the coordination sphere of the metal centres appears to be detrimental to the polymer formation. The room temperature condition, associated with the substantial biocompatibility of niobium, is the most attracting feature which makes the use of $\mathrm{NbCl}_{5}$ in $\beta$-pinene polymerization interesting by industrial point of view, compared to previously employed metal halides (e.g. $\mathrm{AlCl}_{3}$ ). 
According to spectroscopic and analytical studies, the polymerization by niobium halide probably proceeds via cationic mechanism on a niobium-containing cation.

\section{References}

[1] A.R.V. Lawrence, in: D.F. Zinkel, J. Russels (Eds.), Naval Stores, Pulp Chemicals Association, New York, 1989, Chapter 4, p. 123.

[2] E.R. Ruckel, Adhesion Science and Technology, Plenum, New York, 1975.

[3] J.P. Kennedy, Carbocationic Polymerization, Wiley, New York, 1982.

[4] H.F. Mark, N.G. Gaylord, N.M. Bikales, Encyclopedia of Polymer Science and Technology, WileyInterscience, New York, Vol. 31, 1971, p. 575.

[5] (a) F. Cataldo, E. Lilla, O. Ursini, Rad. Phys. Chem. 80 (2011) 723-730, and references therein.

[6] J. Lu, M. Kamigaito, M. Sawamoto, T. Higashimura, Y.-X. Deng, Macromolecules 30 (1997) 22-26.

[7] J. Lu, M. Kamigaito, M. Sawamoto, T. Higashimura, Y.-X. Deng, J. Appl. Polym. Sci. 61 (1996) 1011-1016.

[8] H. Pietila, A. Sivola, H. Sheffer, J. Polym. Sci. Part A-1: Polym. Chem. 8 (1970) 727-737.

[9] W.J. Roberts, A.R. Day, J. Am. Chem. Soc. 72 (1950) 1226-1230.

[10] P.F. Raquel, A.J. Guine, A.M. Castro, J. Appl. Polym. Sci. 82 (2001) 2558-2565.

[11].C. Snyder, W. McIver, H. Sheffer, J. Appl. Polym. Sci. 21 (1977) 131-139. 
[12] J. M. Huet, E. Marechal, C.R. Acad. Sci., Ser. C: Chim. 271 (1970) 1058-1061.

[13] F. Martinez, J. Polym. Sci., Polym. Chem. 22 (1984) 673-677.

[14] (a) H. Zhu, Z. Liu, X. An, F. Lei, Reac. Kinet. Mech. Cat. 100 (2010) 355-361.

(b) H. Zhu, Z. Liu, T. Zhang, W. Zeng, X. An, F. Lei, Reac. Kinet. Mech. Cat. 99 (2010) 463-470.

[15] (a) G. Maccauro, P. Rossi Iommetti, F. Muratori, L. Raffaelli, P. F. Manicone, C. Fabbriciani, Rec.Pat. Biotechnol. 3 (2009) 157-165.

(b) M.H. Fathi, V. Mortazavi, Dental Res. J. 4 (2007) 74-82.

(c) T. Gloriant, G. Texier, F. Prima, D. Lailleé, D.-M. Gordin, I. Thibon, D. Ansel, Adv. Eng. Mat. 8 (2006) 961-965.

(d) D. Velten, E. Eisenbarth, N. Schanne, J. Breme, J. Mater. Sci. Mater. Med. 15 (2004) 457-461.

(e) V.S. Mallela, V. Ilankumaran, N.S. Rao, Indian Pacing Electrophysiol. J. 4 (2004) 201-212.

(f) H. Matsuno, A. Yokoyama, F. Watari, M. Uo, T. Kawasaki, Biomaterials 22 (2001) 1253-1262.

[16] $\mathrm{MF}_{5}(\mathrm{M}=\mathrm{Nb}, \mathrm{Ta})$ have tetranuclear structure in the solid state, while $\mathrm{MX}_{5}(\mathrm{M}=\mathrm{Nb}, \mathrm{Ta} ; \mathrm{X}=\mathrm{Cl}$, $\mathrm{Br}$, I) are dinuclear in the solid state and mononuclear in the vapor phase [A.F. Wells, Structural Inorganic Chemistry, 5th Edition, Clarendon Press, Oxford, 1993]. For sake of simplicity, these compounds will be mentioned in this paper by the empirical formulas $\mathrm{MX}_{5}$.

[17] F. Calderazzo, P. Pallavicini, G. Pampaloni, P.F. Zanazzi, J. Chem. Soc., Dalton Trans. (1990) 2743. 
[18] Y. Buslaev, Y. V. Kukunov, S. M. Kremer, V. A. Shcherbskov, Zh. Neorgan. Materialy 3 (1967) 1424.

[19] P.B. Arimondo, F. Calderazzo, U. Englert, C. Maichle-Mössmer, G. Pampaloni, J. Strähle, J. Chem. Soc., Dalton Trans. 3 (1996) 311-319.

[20] G. R. Willey, T. J. Woodman, M. G. B. Drew, Polyhedron 16 (1997) 351.

[21] F. Marchetti, G. Pampaloni, Y. Patil, A. M. Raspolli Galletti, M. Hayatifar, Polym. Int. DOI 10.1002/pi.3139 (2011)

[22] F. Marchetti, G. Pampaloni, S. Zacchini, Eur. J. Inorg. Chem. (2008) 453.

[23] F. Marchetti, G. Pampaloni, S. Zacchini, J. Fluor. Chem. 131 (2010) 21-28.

[24] W. Willker, D. Leibfritz, R. Kerssebaum, W. Bermel, Magn. Reson. Chem. 31 (1993) 287.

[25] (a) A. Jutand, Eur. J. Inorg. Chem. (2003) 2017.

(b) W.J. Geary, Coord. Chem. Rev. 7 (1971) 81.

[26] D.A. Skoog, D.M. West, Fundamentals of Analytical Chemistry, 2nd Edition, Holt, Rinehart and Winston, Chatham, UK, 1974, p. 233.

[27] J. C. Leasure, C. E. Brinkman, E. S. Tillman, I. W. Monk, N. A. Cohen, Polym. Int. 59 (2010) 642647.

[28] E.Y. Chen, T.J. Marks, Chem. Rev., 100 (2000) 1391-1434.

[29] P. Yu, A. Li, H. Liang, J. Lu, J. Polym. Sci. Part A: Polym. Chem. 45 (2007) 3739-3746. 
[30] (a) D. C. Bradley, I. M. Thomas, Can. J. Chem. 40 (1962) 1355;

(b) Y. Takahashi, N. Onoyama, Y. Ishikawa, S. Motojima, K. Sugiyama, Chem. Lett. (1978) 525.

(c) D. C. Bradley, I. M. Thomas, Can. J. Chem. 40 (1962) 449.

(d) W. A. Nugent, D. W. Ovenall, S. J. Holmes, Organometallics 2 (1983) 161.

(e) X.-H. Zhang, S.-J. Chen, H. Cai, H.-J. Im, T. Chen, X. Yu, X. Chen, Z. Lin, Y.-D. Wu, Z.-L. Xue, Organometallics 27 (2008) 1338.

[31] F. Marchetti, G. Pampaloni, Y. Patil, A. M. Raspolli Galletti, S. Zacchini, J. Polym. Sci., Part A: Polymer Chem. 49 (2011) 1664-1670.

[32] K. Mashima, S. Fujikawa, H. Urata, E. Tanaka, A. Nakamura, J. Chem. Soc., Chem. Commun. (1994) 1623-1624.

[33] A.M. Raspolli Galletti, G. Pampaloni, A. D’Alessio, Y. Patil, F. Renili, S. Giaiacopi, Macromol. Rapid Commun. 30 (2009) 1762-1768.

[34] F. Marchetti, G. Pampaloni, Y. Patil, A.M. Raspolli Galletti, F. Renili, S. Zacchini, Organometallics 30 (2011) 1682-1688.

[35](a) R. Bini, F. Marchetti, G. Pampaloni, S. Zacchini, Polyhedron 30 (2011) 1412-1419.

(b) F. Marchetti, G. Pampaloni, S. Zacchini, Eur. J. Inorg. Chem. (2010) 767-774.

(c) R. Bini, C. Chiappe, F. Marchetti, S. Zacchini, G. Pampaloni, Inorg. Chem. 49 (2010) 339-351.

(d) F. Marchetti, G. Pampaloni, S. Zacchini, Dalton Trans. (2009) 8096-8106.

[36] The $\mathrm{C}=\mathrm{C}$ bond stretching vibration of the uncoordinated $\beta$-pinene falls at $1642 \mathrm{~cm}^{-1}$ (liquid film). 
[37] $\mathrm{NbF}_{5}(0.640 \mathrm{mmol}), \mathrm{CD}_{2} \mathrm{Cl}_{2}(0.70 \mathrm{mmol})$ and $\beta$-pinene $(0.640 \mathrm{mmol})$ were introduced into a NMR tube in the order given. Then the tube was sealed and shaken briefly in order to homogenize the content. NMR analyses on the dark red solution were recorded after 2 hours. ${ }^{1} \mathrm{H}$ NMR $\left(\mathrm{CDCl}_{3}\right): \delta=$ 7.62, 7.06 (br), 2.9-0.8 ppm (br). ${ }^{19} \mathrm{~F}$ NMR $\left(\mathrm{CD}_{2} \mathrm{Cl}_{2}\right): \delta=158.8 \mathrm{ppm}\left(\Delta_{v}=262 \mathrm{~Hz}\right) .{ }^{19} \mathrm{~F} \mathrm{NMR}$ $\left(\mathrm{CD}_{2} \mathrm{Cl}_{2}, 211 \mathrm{~K}\right): \delta=158.8 \mathrm{ppm}\left(\Delta_{v}=262 \mathrm{~Hz}\right)$. Analogous experiment was carried out by using $\mathrm{NbCl}_{5}(0.760 \mathrm{mmol})$ and $\beta$-pinene $(0.760 \mathrm{mmol}) .{ }^{1} \mathrm{H} \mathrm{NMR}\left(\mathrm{CDCl}_{3}\right): \delta=7.24,7.02(\mathrm{br}), 2.9-0.9 \mathrm{ppm}$ (br).

\section{Captions for Figures and Tables}

Figure 1. Schematic representation of cationic polymerization of of $\beta$-pinene.

Figure 2. ${ }^{1} \mathrm{H} \mathrm{NMR}$ of poly( $\beta$-pinene) obtained with $\mathrm{NbCl}_{5}$ as catalytic precursor in Run 17.

Figure 3. FT-IR Spectra of poly( $\beta$-pinene) obtained with $\mathrm{NbCl}_{5}$ as catalytic precursor in Run 17 .

Table 1. Lewis acid catalyzed polymerization of $\beta$-pinene $[7,8,9,10]^{\mathrm{a}}$

Table 2. Polymerization of $\beta$-pinene in the presence of $\mathrm{NbCl}_{5} /$ alkylaluminium compounds ${ }^{\text {a }}$

Table 3. Polymerization of $\beta$-pinene catalyzed by $\mathrm{Nb}(\mathrm{V})$ and $\mathrm{Ta}(\mathrm{V})$ halides ${ }^{\mathrm{a}}$ 
Figure 1

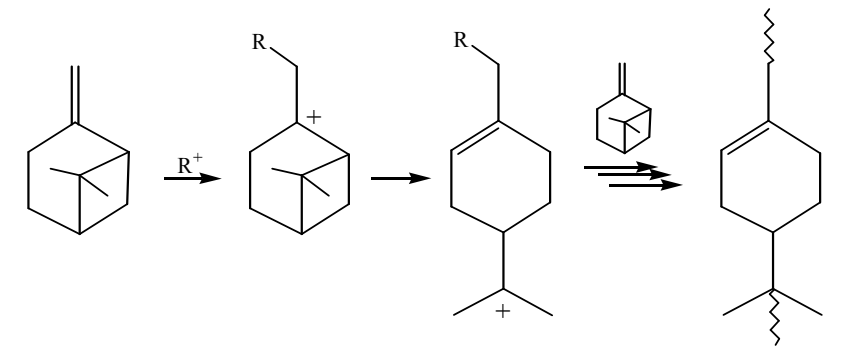


Figure 2

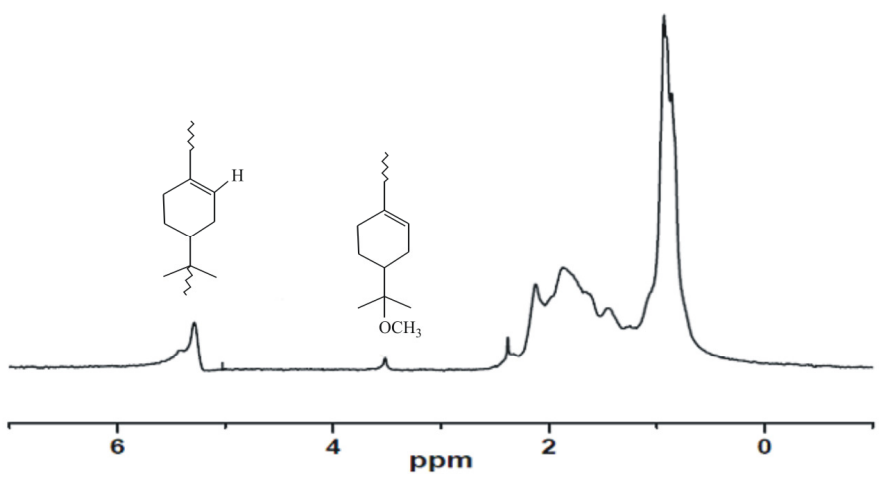


Figure 3

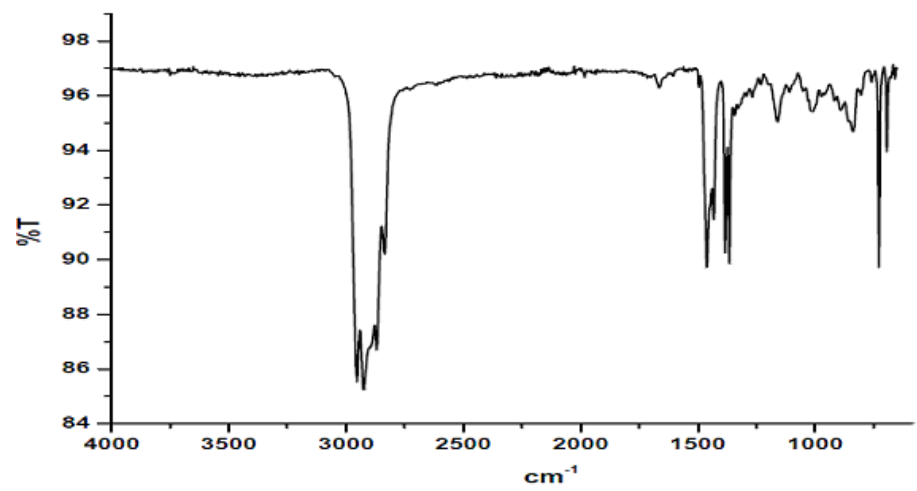




\section{Table 1}

\begin{tabular}{|c|c|c|c|c|c|c|c|}
\hline Run & $\begin{array}{c}\text { Catalyst } \\
{[\mathrm{M}]}\end{array}$ & $\begin{array}{c}\beta \text {-pinene } \\
{[\mathrm{M}]}\end{array}$ & $\begin{array}{c}\text { Time } \\
(\mathrm{min})\end{array}$ & $\begin{array}{c}\text { Temp. } \\
\left({ }^{\circ} \mathrm{C}\right)\end{array}$ & $\begin{array}{c}\text { Conversion } \\
(\%)\end{array}$ & $\mathrm{M}_{\mathrm{n}}{ }^{\mathrm{b}}$ & Ref. \\
\hline 1 & $\mathrm{AlCl}_{3}[0.4]$ & 1.8 & 10 & -40 & 100 & 4400 & 7 \\
\hline 2 & $\begin{array}{c}\mathrm{AlCl}_{3} / \mathrm{SbCl}_{3} \\
{[0.2]}\end{array}$ & 1.8 & 10 & -40 & 100 & 3900 & 7 \\
\hline 3 & $\mathrm{AlCl}_{3}[0.04]^{\mathrm{c}}$ & 1.4 & 60 & 30 & 20 & 1890 & 8 \\
\hline 4 & $\mathrm{AlCl}_{3}[0.05]$ & 0.5 & 10 & 45 & 94 & $1500^{\mathrm{c}}$ & 9 \\
\hline 5 & $\begin{array}{c}\mathrm{AlCl}_{3} \cdot \mathrm{Et}_{2} \mathrm{O} \\
{[0.05]}\end{array}$ & 0.5 & 10 & 45 & 76 & $1500^{\mathrm{c}}$ & 9 \\
\hline 6 & $\mathrm{AlBr}_{3}[0.05]$ & 0.5 & 10 & 45 & 93 & $1500^{\mathrm{c}}$ & 9 \\
\hline 7 & $\mathrm{ZrCl}_{4}[0.05]$ & 0.5 & 10 & 45 & 96 & $1500^{\mathrm{c}}$ & 9 \\
\hline 8 & $\mathrm{BF}_{3}[0.05]$ & 0.5 & 10 & 45 & 54 & $1500^{\mathrm{c}}$ & 9 \\
\hline 9 & $\begin{array}{c}\mathrm{BF}_{3} . \mathrm{Et}_{2} \mathrm{O} \\
{[0.05]}\end{array}$ & 0.5 & 10 & 45 & 43 & $1500^{\mathrm{c}}$ & 9 \\
\hline 10 & $\mathrm{SnCl}_{4}[0.05]$ & 0.5 & 10 & 45 & 21 & $1500^{\mathrm{c}}$ & 9 \\
\hline 11 & $\mathrm{BiCl}_{3}[0.05]$ & 0.5 & 10 & 45 & 5 & $1500^{\mathrm{c}}$ & 9 \\
\hline 12 & $\mathrm{SnCl}_{3}[0.05]$ & 0.5 & 10 & 45 & 0.7 & $1500^{\mathrm{c}}$ & 9 \\
\hline 13 & $\mathrm{ZnCl}_{2}[0.05]$ & 0.5 & 10 & 45 & 0.5 & $1500^{\mathrm{c}}$ & 9 \\
\hline 14 & $\begin{array}{c}\mathrm{C}_{2} \mathrm{H}_{5} \mathrm{AlCl}_{2} \\
{[0.6]}\end{array}$ & 4.4 & 120 & 10 & 90.3 & 2432 & 10 \\
\hline 15 & $\begin{array}{c}\mathrm{C}_{2} \mathrm{H}_{5} \mathrm{AlCl}_{2} \\
{[0.6]}\end{array}$ & 4.4 & 120 & 20 & 90.2 & 1500 & 10 \\
\hline 16 & $\begin{array}{c}\mathrm{C}_{2} \mathrm{H}_{5} \mathrm{AlCl}_{2} \\
{[0.6]}\end{array}$ & 4.4 & 120 & 50 & 90.4 & 1128 & 10 \\
\hline
\end{tabular}

${ }^{a}$ Solvent: toluene.

${ }^{\mathrm{b}}$ Determined by GPC, unless otherwise specified.

${ }^{c}$ Solvent: xylene.

${ }^{\mathrm{d}}$ Average molecular weight obtained by cryoscopic methods 


\section{Table 2}

\begin{tabular}{|c|c|c|c|c|c|c|c|}
\hline Run & $\begin{array}{c}\mathbf{1 b} \\
(\mu \mathrm{mol})\end{array}$ & $\begin{array}{c}\text { Co- } \\
\text { catalyst }\end{array}$ & $\begin{array}{c}\mathrm{Al} / \mathrm{Nb} \\
(\mathrm{mol} / \mathrm{mol})\end{array}$ & $\begin{array}{c}\text { Temp. } \\
\left({ }^{\circ} \mathrm{C}\right)\end{array}$ & $\begin{array}{c}\text { Conversion } \\
(\%)\end{array}$ & $\mathrm{M}_{\mathrm{n}}^{\mathrm{b}}$ & $\mathrm{DPI}^{\mathrm{b}}$ \\
\hline 17 & 15 & - & - & R.T. & 98 & 1442 & 3.4 \\
\hline $18^{\mathrm{c}}$ & 15 & - & - & R.T. & 97 & 1288 & 3.1 \\
\hline 19 & - & - & - & R.T. & 0 & - & - \\
\hline 20 & 15 & - & - & 0 & 18 & 1587 & 2.1 \\
\hline 21 & 15 & - & - & 50 & 8 & 1125 & 2.3 \\
\hline $22^{\mathrm{d}}$ & 15 & - & - & R.T. & 4 & n.d. ${ }^{\mathrm{e}}$ & - \\
\hline $23^{f}$ & 15 & - & - & R.T. & 67 & 1256 & 2.5 \\
\hline 24 & 30 & - & - & R.T. & 97 & 1189 & 3.1 \\
\hline 25 & 15 & $\mathrm{MAO}$ & 500 & R.T. & 98 & 1479 & 3.5 \\
\hline 26 & 15 & TMA & 50 & R.T. & 10 & 1460 & 2.3 \\
\hline 27 & 15 & TIBAL & 50 & R.T. & 66 & 1269 & 2.7 \\
\hline 28 & - & $\mathrm{MAO}^{\mathrm{g}}$ & - & R.T. & Trace & - & - \\
\hline 29 & - & TMA $^{\mathrm{h}}$ & - & R.T. & 0 & - & - \\
\hline 30 & - & TIBAL $^{1}$ & - & R.T. & 0 & - & - \\
\hline 31 & - & EADC $^{\mathrm{j}}$ & - & R.T. & 69 & 1379 & 2.8 \\
\hline 32 & - & DEAC $^{\mathrm{k}}$ & - & R.T. & 85 & 1242 & 2.7 \\
\hline 33 & 15 & EADC & 50 & R.T. & 86 & 1201 & 3.4 \\
\hline 34 & 15 & DEAC & 50 & R.T. & 95 & 1188 & 3.1 \\
\hline
\end{tabular}

${ }^{a}$ Reaction Conditions: Toluene $(20 \mathrm{~mL}),[\beta$ - pinene $]=1.2 \mathrm{M}$, reaction time $5 \mathrm{~h}$

${ }^{\mathrm{b}}$ Determined by GPC.

${ }^{\mathrm{c}}$ Absence of light.

${ }^{\mathrm{d}}$ Solvent: chlorobenzene.

${ }^{\mathrm{e}}$ Not determined

${ }^{\mathrm{f}}$ Reaction time: $1 \mathrm{~h}$

${ }^{\mathrm{g}} \mathrm{MAO}=4.97 \mathrm{~mL}$.

h $\mathrm{TMA}=0.75 \mathrm{~mL}$.

i. $\mathrm{TIBAL}=0.41 \mathrm{~mL}$.

${ }^{\mathrm{j}} \mathrm{EADC}=0.41 \mathrm{~mL}$.

${ }^{\mathrm{k}} \mathrm{DEAC}=0.40 \mathrm{~mL}$. 
Table 3

\begin{tabular}{|c|c|c|c|c|}
\hline Run & Precursor & $\begin{array}{c}\text { Conversion } \\
(\%)\end{array}$ & $\mathrm{M}_{\mathrm{n}}{ }^{\mathrm{b}}$ & PDI $^{\mathrm{b}}$ \\
\hline 35 & $1 \mathrm{a}$ & 85 & 720 & 4.1 \\
\hline 36 & $1 \mathrm{c}$ & 92 & 830 & 2.9 \\
\hline 37 & $1 \mathrm{~d}$ & 0 & & \\
\hline 38 & $\mathrm{NbF}_{4}(\mathrm{OPh})$ & 42 & 610 & 3.1 \\
\hline 39 & $\mathrm{NbF}_{5}(\mathrm{EtOH})$ & 0 & & \\
\hline 40 & $\mathrm{NbCl}_{5}(\mathrm{MeCN})$ & Trace & & \\
\hline 41 & $\mathrm{NbCl}_{5}\left(\mathrm{Ph}_{2} \mathrm{CO}\right)$ & 0 & & \\
\hline 42 & $\mathrm{NbCl}_{5}\left[\left(\mathrm{NMe}_{2}\right)_{2} \mathrm{CO}\right]$ & 0 & & \\
\hline 43 & $2 \mathrm{a}$ & 77 & 750 & 2.9 \\
\hline 44 & $2 \mathrm{~b}$ & Trace & & \\
\hline $45^{\mathrm{c}}$ & \left.${\mathrm{Nb}\left(\mathrm{O}_{2} \mathrm{CNEt}\right.}_{2}\right)_{5}$ & 0 & & \\
\hline $46^{\mathrm{c}, \mathrm{d}}$ & \left.${\mathrm{Nb}\left(\mathrm{O}_{2} \mathrm{CNEt}\right.}_{2}\right)_{5}$ & Trace & & \\
\hline $47^{\mathrm{c}}$ & $\mathrm{Ta}\left(\mathrm{O}_{2} \mathrm{CNEt}_{2}\right)_{5}$ & 0 & & \\
\hline $48^{\mathrm{c}, \mathrm{d}}$ & $\mathrm{Ta}\left(\mathrm{O}_{2} \mathrm{CNEt}_{2}\right)_{5}$ & Trace & & \\
\hline
\end{tabular}

${ }^{a}$ Reaction Conditions: Precursor: $15 \mu \mathrm{mol},[\beta$ - pinene $]=1.2 \mathrm{M}$, toluene $(20 \mathrm{~mL}), \mathrm{t}=5 \mathrm{~h}, \mathrm{~T}$ $=25{ }^{\circ} \mathrm{C}$.

${ }^{\mathrm{b}}$ Determined by GPC.

${ }^{c}$ Precursor: $30 \mu \mathrm{mol}$.

${ }^{\mathrm{d}} \mathrm{MAO}$ was added as co-catalyst $(\mathrm{Al} / \mathrm{Nb}=500 \mathrm{~mol} / \mathrm{mol})$. 